\title{
Metodo de gestão em sistema de produção animal
}

\author{
Paulo Fernando Machado ${ }^{1}$, Laerte Dagher Cassoli ${ }^{2}$, Augusto Lima da Silva ${ }^{3}$
}

\author{
${ }^{1}$ ESALQ-USP. \\ ${ }^{2}$ ESALQ-USP. \\ 3 Clínica do Leite.
}

RESUMO - O sistema MDA de gerenciamento de explorações leiteiras teve origem em um conjunto de práticas gerenciais desenvolvidas e utilizadas eficientemente pelo setor industrial desde o início da década de 90. Foi desenvolvido aplicando-se os cinco princípios administrativos básicos para se atingir o sucesso nas empresas. Estes princípios, somados aos princípios de sobrevivência na atividade nortearam as características do Sistema MDA. Ele pode ser caracterizado como um sistema de gestão estratégica que se inicia com os fins em mente, ou seja, é condição básica para a realização de qualquer tarefa a definição, a priori, de metas e prazos. Com isso infere-se que há necessidade de se medir coisas. Se os resultados não forem alcançados, devem-se procurar as causas no treinamento dos funcionários ou nos métodos utilizados e nunca nas pessoas. Também, devese satisfazer a todos os interessados no negócio - os acionistas, os clientes, os funcionários e a sociedade.

Palavras-chave: gerenciamento, gestão da rotina, pecuária de leite, plano de negócios, recursos humanos

\section{Management method in animal production system}

\begin{abstract}
The MDA (Master Dairy Administration) system was created as a result of management practices developed by and effectively utilized in the industrial sector since the early 1990's. It was designed by applying the five basic management principles to reach success in business. These principles, along with survival principles in the activity, delineated the features of the MDA System. It can be characterized as a strategic system which targets the ends from start, that is, the definition, a prior, of targets and deadlines is a primary condition to carry out any task. Therefore, there is a need to measure and follow up procedures. If results are not reached, questions must be placed on the training offered to employees or on the methods utilized, but never on the people. Moreover, all people interested in the business must have their expectations met shareholders, customers, employees and the society.
\end{abstract}

Key Words: business planning, dairy cattle, management, human resources, routine management

\section{Introdução}

\section{O Sistema MDA - visão geral}

O Sistema MDA é umsistema de gestão de explorações leiteiras. Ele se fundamenta na realização de ações com os fins em mente, ou seja, é condição básica para a realização de qualquer tarefa a definição, a priori, de metas e prazos. Devem ser definidas as metas de longo prazo (05 anos), assim como as de curto prazo (01 ano) e as de curtíssimo prazo (01 dia). As metas devem, obrigatóriamente satisfazer a todos os interessados no negócio - os acionistas, os clientes, os funcionários e a sociedade. As tarefas são, então, executadas com o fim de se atingir estas necessidades. Também, na realização das tarefas procura-se a consistência dos resultados. Com isso infere-se que há necessidade de se medir coisas. O
Sistema utiliza intensamente de indicadores de eficiência. Muitos destes indicadores identificam anormalidades antes do produto da(s) tarefa(s) estar pronto, como no programa APPCC de controle de pontos críticos aplicados na indústria de alimentos. Se, no entanto, os resultados não são alcançados, o Sistema preconiza que deve-se procurar as causas no treinamento dos funcionários ou nos métodos utilizados e nunca nas pessoas. Ou seja, devese mudar o foco das pessoas para os processos. Onde os métodos são os problemas, retreinam-se pessoas, melhoram-se os processos, enfim procura-se o que está errado e não quem errou.

Ele teve origem em um conjunto de práticas gerenciais utilizadas desde há muito tempo, de maneira eficiente, pelo setor industrial. Ele foi desenvolvido pela Clínica do Leite da ESALQ-USP, aplicando-se os cinco princípios 
administrativos básicos para se atingir o sucesso nas empresas:

1. Princípio da objetividade: é a definição clara e escrita da missão, visão, valores e metas do negócio;

2. Princípio da coordenação: consiste no estabelecimento dos procedimentos operacionais das rotinas, integrando o sistema de produção (estratégia) com os recursos disponíveis e fazendo com que todos entendam o papel e função de cada unidade operacional;

3. Princípio da autoridade e responsabilidade: quando um indivíduo recebe uma tarefa deve, também, receber a autoridade para cumpri-la;

4. Princípio da unidade de comando: onde cada empregado deve responder para somente uma pessoa; e

5. Princípio da delegação: é o processo de definir responsabilidades e conferir autoridade para que as atividades sejam cumpridas.

O sucesso do Sistema, no entanto, exige uma nova postura, principalmente do proprietário, em relação ao negócio e às pessoas. Ele precisa entender que o negócio não é somente dele, mas também dos clientes, dos funcionários e da sociedade. Que ele está entrando com o capital e, eventualmente, com serviços específicos (gerenciamento) e que os funcionários, além dos serviços, também estão entrando com capital, porém na forma intangível (conhecimento), que, se não houver clientes e que, se a sociedade for contrária ao negócio (por exemplo: contaminação ambiental), a empresa não sobreviverá. É, também, condição básica para o sucesso do Sistema a escolha do gerente da propriedade. Ele poderá ser o próprio acionista ou alguém por ele contratado. De qualquer maneira ele deverá reunir características de liderança sobre seus colaboradores. O gerente precisa ser treinado para destinar seu tempo para coisas consideradas importantes e prioritárias, profissionalmente ou pessoalmente. Depreendese, com isso, que o gerente deverá se dedicar mais às pessoas do que aos animais; deverá ter a habilidade de perceber sinais de falta de motivação nos seus comandados e se responsabilizar pelo atingimento das metas. Para tanto, deverá, também, ser treinado para delegar tarefas não importantes.

Os componentes do Sistema MDA podem ser observados na figura 1. Eles formam um círculo de tarefas que podem ser implantadas concomitantemente ou em sequência. Neste trabalho discutiremos somente parte de alguns de seus componentes (Plano de Negócios, Gestão de Recursos Humanos e Gestão da Rotina).

\section{Plano de negócios}

O Plano de negócios é a definição clara, objetiva e por

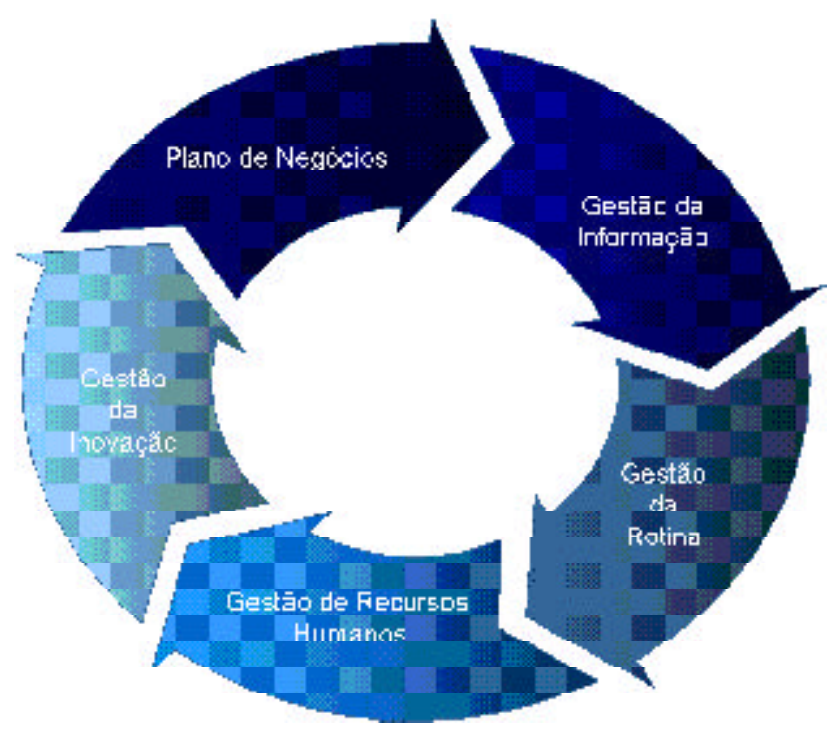

Figura 1 - Círculo de tarefas do Sistema MDA

escrito, para um prazo de 05 anos, do que é o negócio e de sua viabilidade. Ele é composto pela descrição da missão, visão, valores, sistema de produção, metas de longo prazo, análise de viabilidade econômico-financeira e manual de recursos humanos. Neste trabalho vamos discutir com mais detalhes somente a definição de negócio.

\section{Definição de negócio (em que negócio estamos)}

Antes de se iniciar qualquer negócio é preciso caracterizá-lo e, para tanto, é necessário que se conheçam quais são os princípios básicos para a sua sobrevivência.

O negócio deve ser caracterizado sempre do fim para o começo, ou seja, o fim de qualquer negócio é o atendimento das necessidades de seus interessados. Todo negócio possui quatro interessados: seus clientes (mercado consumidor), seus acionistas ou proprietários (mercado financeiro), seus funcionários (mercado de trabalho) e, finalmente, a sociedade (mercado amplo). Sem que sejam atendidas as necessidades de todos os seus interessados, um negócio não sobrevive; fecha; está fadado ao insucesso.

As necessidades dos clientes estão intimamente relacionadas ao produto:qualidade (sabor, cor, odor, valor nutritivo), itens de entrega (quanto, onde, quando, comodidade/embalagem), custo (não adianta o produtor simplesmente estipular arbitrariamente um preço para o seu produto: o preço nunca será maior que aquele que o consumidor pode pagar), por exemplo, de nada adianta estabelecer um preço de venda do litro de leite a $\mathrm{R} \$ 5,00$, pois, sabe-se que tal valor nunca será pago, e, finalmente, segurança (ao se consumir o produto), por exemplo, ausência 
de antibiótico e/ou outros resíduos no leite.

A necessidade dos acionistas é o retorno sobre o capital investido $(R S C)$ maior ou, pelo menos igual, à de alguma aplicação financeira, geralmente a poupança. A empresa produtora de leite somente tem sua sobrevivência assegurada ao longo das gerações se der lucro, diferentemente de alguns outros negócios, como a medicina, por exemplo. Além do RSC é imperativo que a empresa faça caixa para fazer frente as suas obrigações de curto e médio prazo.

As necessidades dos funcionários são o atendimento dos direitos trabalhistas, boas condições de trabalho, salário justo e respeito.

A necessidade da sociedade, por sua vez, se relaciona com os valores éticos (preservação dos recursos naturais, respeito à legislação, pagamento de tributos, etc.).

Conhecidas as necessidades de todos os interessados, pode-se, a partir delas, caracterizar os produtos do negócio, lembrando que produto é qualquer coisa que é do interesse de alguém. Com isso saberemos em que negócio estamos e o que teremos de fazer para atender as necessidades dos interessados.

\section{Gestão de recursos humanos}

O Sistema MDA propõe, não somente, a adoção de práticas e ferramentas gerenciais, mas, também, uma mudança na forma de se encarar o negócio, ou seja, uma mudança de foco administrativo, uma nova maneira de pensar de todos aqueles que estejam envolvidos com o negócio.

A maneira tradicional de se administrar é centrada, principalmente, nas pessoas ou meios, quando o correto é se concentrar nos resultados dos procedimentos. Quando os resultados obtidos não são bons, ou seja, quando as metas não estiverem sendo atingidas, o procedimento que foi adotado não é bom ou, então, o mesmo não está sendo realizado conforme o combinado. Diante de uma tarefa executada fora das conformidades existem dois tipos de funcionários, o funcionário mau caráter, que é facilmente identificável e que deve ser dispensado o mais breve possível, e o funcionário mal treinado, que não executou o procedimento da maneira correta porque não sabia como fazê-lo e, portanto, é isento de culpa, devendo ser, então, treinado ou retreinado.

Fazer as tarefas corretamente é fazer as coisas conforme foram combinadas, sempre da mesma maneira, o que pode ser verificado através dos indicadores. A garantia de que estas tarefas serão cumpridas conforme o combinado não é conseguida a partir da fiscalização durante a sua execução, mas sim a partir do comprometimento dos próprios operadores em atingir as metas predeterminadas. Este comprometimento é conseguido a partir de técnicas de motivação, que não serão abordadas neste trabalho.

Os empregados são considerados, por muitos, o principal problema da pecuária leiteira. $\mathrm{Na}$ realidade, o principal problema da atividade (dentro da porteira) é o gerenciamento inadequado. Muitos proprietários são empresários bem sucedidos em outras atividades e, no entanto ao gerenciarem suas respectivas propriedades não obtém sucesso financeiro, passando a preocupar-se demasiadamente com questões técnicas (que também são importantes), deixando de encarar a fazenda como uma empresa, como um negócio. Passam então a cometer erros primários que, em suas empresas seriam considerados absurdos, impensáveis, como, por exemplo, investimentos elevados em instalações e máquinas realizados sem que se saiba se são realmente necessários ou se trarão algum retorno.

Ao se responsabilizar funcionários pelo insucesso do negócio é preciso antes lembrar das seguintes frases: "O seu negócio é tão bom quanto o são seus funcionários" e "Os seus empregados são tão bons quanto o é seu gerenciamento", logo, através da união destas frases, conclui-se que "O seu negócio é tão bom quanto o é seu gerenciamento".

Organização dos recursos humanos em fazendas leiteiras

As tarefas executadas em uma propriedade leiteira independem de seu tamanho. Deve-se ordenhar as vacas, alimentá-las, limpar pisos e cochos, cuidar dos animais doentes, etc. Todas estas tarefas são consideradas operacionais. Para que elas sejam executadas corretamente há necessidade de treinar os operadores e medir coisas com o objetivo de se verificar se as metas estão sendo atingidas. A definição de metas exige o planejamento à priori e a elaboração de planos de ação para o atingimento destas metas.

As tarefas administrativas podem ser agrupadas da seguinte maneira:

1. Planejamento, que inclui a definição da missão, visão, valores incluindo as metas a serem atingidas a curto, médio e longo prazo e os métodos empregados.

2. Organização, que envolve o estabelecimento da estrutura da organização, definindo o papel e funções das pessoas para se atingir a missão do negocio, assim como as responsabilidades e autoridade das pessoas, ou seja, a definição do organograma da empresa.

3. Seleção, ou seja, controlar, treinar, e avaliar pessoas. Encontrar a pessoa certa para cada função. 
4. Direção, que é, liderar, ensinar, delegar e motivar pessoas. Para tanto é necessário comunicar-se com as pessoas com o objetivo de desenvolver e melhorar o ambiente de trabalho.

5. Controle, que é medir e reportar os indicadores de eficiência, analisando-os e tomando medidas corretivas.

Observa-se que é bastante difícil que uma pessoa tenha a habilidade e o tempo necessário para executar todas as tarefas mencionadas acima, principalmente quando o número de animais é grande. Com isso, distribui-se o trabalho para diferentes pessoas, dando-lhes funções claras e específicas.

As funções podem ser agrupadas em operacionais e gerenciais. As operacionais subdivididas em operação e supervisão e as gerenciais em direção e gerenciamento. A mesma pessoa pode executar todas as funções mencionadas, dividindo seu tempo entre elas de acordo com o cargo que ocupa na empresa. Assim, o proprietário pode exercer somente a função de direção (em empresas maiores) ou as quatro funções mencionadas (em empresas menores). Em algumas empresas o proprietário é o diretor e gerente, enquanto que os funcionários são operadores e supervisores.

Ao diretor cabe a responsabilidade de escolher o rumo certo a seguir. Para tanto deve definir a estratégia do negócio, suas metas de médio e longo prazo, o planejamento estratégico de curto prazo (um ano), a aprovação dos investimentos e dos planos de inovação e o acompanhamento da implantação dos planos de ações.

Ao gerente cabe a responsabilidade de atingir as metas. Para tanto deve propiciar condições de trabalho aos supervisores e operadores, organizando-os hierarquicamente, atribuindo tarefas específicas e responsabilidades no atingimento de metas, elaborar protocolos operacionais, analisar as anomalias e garantir o bem estar e a motivação dos funcionários.

Ao supervisor cabe a responsabilidade de fazer com que as operações sejam realizadas como previstas, sem interrupções. Para tanto deve treinar os operadores, fazer as medições para o cálculo dos indicadores de desempenho e corrigir, de imediato, as anomalias, sob sua autoridade.

Aos operadores cabe a responsabilidade de executar as tarefas operacionais conforme recomendado e identificar as anomalias. Para tanto devem receber o treinamento adequado e os materiais e facilidades necessários.

Existem outros colaboradores importantes para o sucesso do empreendimento. São os consultores. As propriedades leiteiras possuem contato periódico com grande número de consultores. São profissionais que fazem recomendações técnicas (balanceamento de dietas, recomendação de adubação, programas de vacinação, etc.), atividades operacionais (palpações, cirurgias, etc.), ou mesmo sugestões gerenciais (planejamento estratégico, avaliação financeira e zootécnica, etc.). Estes profissionais devem responder a diferentes indivíduos dentro do negócio dependendo do tipo de tarefa que estão executando. No caso de trabalhos gerenciais devem responder para o proprietário, no caso de operacionais, aos supervisores e, no caso, de recomendações técnicas, ao gerente/ administrador.

Os consultores não são responsáveis pelos resultados do negócio. Eles são responsáveis pela recomendação/ parecer/sugestão técnica, ou, no caso de um trabalho operacional, como palpação, por exemplo, pela correção do ato. O resultado final (atingimento de metas) é, sempre, de responsabilidade do gerente. Se as metas foram atingidas e, mesmo assim, o negócio não se mostra sustentável, a responsabilidade deve ser atribuída ao diretor/proprietário.

Observa-se que, nas funções listadas acima para o gerente, a maior parte do seu tempo deve se concentrar nas tarefas consideradas importantes, porém não urgentes como contratar e treinar pessoas, analisar indicadores e elaborar planos de correção das anomalias e, a outra parte (menor), nas consideradas importantes e urgentes como corrigir anomalias - por exemplo, leite condenado, quebra de equipamento de ordenha, etc. O que se vê, no entanto, em algumas propriedades, é a utilização do tempo em coisas não importantes e não urgentes, como execução de tarefas operacionais, participação em palestras sobre assuntos que não estão relacionados à solução de problemas de atingimento de metas ou mesmo em atividades não importantes e consideradas urgentes, como atendimento a telefonemas, visitas, etc. Para tanto, é fundamental que o gerente seja treinado para delegar tarefas.

Apesar da importância de delegar, muitas vezes isso não é feito por diversos motivos, dentre eles, pode-se citar:

- Falta de estrutura organizacional: não se sabe que é quem, quem manda em quem e quem responde a quem;

- Falta de procedimentos operacionais: não se sabe como as tarefas devem ser executadas;

- Falta de metas: não se pode delegar antes que se tenham definidos os resultados que se deseja atingir, ou seja, quando não se sabe o que se deseja do funcionário;

Falta de confiança nos funcionários: desconfia-se da honestidade dos empregados. Tem-se o conceito generalizado de que os funcionários são ruins, preguiçosos e que só fazem as coisas quando fiscalizados;

- Sensação de perda de controle: o gerente assume todas as atividades a serem executadas porque tem a 
impressão de que, delegando, perde o controle da situação. Que, se outros souberem executar suas tarefas, ele deixa de ser importante para a fazenda. Isto não é verdade. Uma pessoa é tão importante quanto as metas que ela atinge e não tão mais importante quanto as tarefas que ela executa.

É incontestável a importância de se delegar. Existem, no entanto, funções que não podem ser delegadas e que cabem somente ao gerente, como, por exemplo, a seleção e demissão de pessoas.

\section{Gestão da rotina}

Da mesma maneira que há uma tendência em definirmos os nossos produtos sem observarmos quais são as reais necessidades dos nossos clientes, há também uma tendência em alterarmos os processos sem que se saiba se estas alterações são realmente necessárias.

Por julgarmos que os processos não estão adequados e que eles são os responsáveis pelo insucesso na atividade, fazemos alterações nos mesmos, quando, na realidade, nem sabemos, sequer, identificar se existe problema. O correto seria identificar o problema, suas causas, e planejar as ações corretivas para, posteriormente, implantá-las, medilas e torná-las permanentes.

Um exemplo clássico é o da formulação de dietas para vacas em lactação. O que se observa, na maioria dos casos, é que, a cada visita do técnico contratado, que geralmente é mensal, muda-se a dieta dos animais (incluemse alimentos diferentes). Para o técnico e para o produtor estas alterações são indispensáveis, visto que é para isto que o consultor foi contratado. Muitas vezes estas mudanças não são necessárias. Deste modo, não é possível avaliar o efeito das mudanças promovidas, já que, normalmente, o impacto da dieta é por tempo prolongado. Assim, a partir de mudanças sucessivas, eventualmente, retorna-se a uma dieta já adotada anteriormente. Começa-se a andar em círculos (e não para frente); não se evolui como deveria ocorrer.

Esta tendência em se promover mudanças é bastante comum à maioria dos técnicos que, durante sua formação acadêmica recebeu maior ênfase na parte técnica, fazendo com que os conhecimentos gerenciais fossem negligenciados. Entretanto, não somente o profissional deve ser responsabilizado por tal postura inadequada, em muitos casos, as mudanças são resultantes da pressão exercida pelo proprietário da fazenda, que avalia o desempenho do assistente técnico através dos serviços prestados e não dos resultados obtidos, julgando inadmissível o consultor visitar sua propriedade e não prestar serviços técnicos, em outras palavras, não promover mudanças na dieta.

A quantidade de mudanças que são feitas, a todo momento, nas propriedades, é tamanha, que gera grande inconsistência nos resultados, ou seja, uma grande variação. Enfim, não se tem rotina, a cada hora as tarefas são executadas de uma maneira, sem que se saiba qual o modo mais adequado de executá-las. É neste contex to que se justifica a Gestão da Rotina. Ela diz respeito à sistematização das operações do dia-a-dia.

O primeiro passo na sistematização da rotina é a elaboração do "Fluxograma dos produtos". Ele deve ser executado para todos os produtos de cada setor da propriedade. Para tanto, deve-se ter definidos, claramente, os setores e seus produtos. O fluxograma dos produtos é a representação esquemática do conjunto de tarefas necessárias à transformação dos insumos em produtos. Cada fluxograma pode ser definido como um processo de obtenção do produto.

O fluxograma deve ter início e fim claramente definidos e deve conter somente tarefas que realmente contribuem e que são criticas para a obtenção dos produtos finais. A identificação destas tarefas deve ser feita in loco, ou seja, a campo, acompanhando diretamente o processo de obtenção do produto.

O fluxograma tem por objetivo facilitar a visualização, dando um melhor entendimento das tarefas, de maneira a oferecer condições para que qualquer indivíduo seja capaz de realizá-las até a obtenção do produto final. Também, através dele, é possível visualizar tarefas desnecessárias, que são sinônimo de custo e conseqüentemente de prejuízo. Definidos os fluxogramas é possível escrever os protocolos operacionais (PO's) das tarefas que compõem os fluxogramas. Os PO's são a descrição detalhada, passo a passo, de como as tarefas devem ser realizadas.

Como o número de PO's é elevado, deve-se, primeiramente, identificar quais são os processos que possuem problemas ou, no caso de uma exploração ainda não existente, aqueles que são prioritários. Identificados os processos, deve-se verificar quais as atividades críticas e, a partir daí, escrever os protocolos para estas atividades. Com isso estaremos trabalhando com um menor número de atividades e somente com aquelas que estão afetando os nossos produtos.

Os PO's são a descrição detalhada, passo a passo, de como as tarefas devem ser executadas. Não importa o formato como o PO é escrito, o que realmente importa é que ele seja feito de maneira que as pessoas saibam exatamente o que e como fazer, e que executem as tarefas sempre da 
mesma maneira, como foi combinado, para que assim os objetivos sejam atingidos. Os POs devem ser feitos para os funcionários. Devem, portanto, ser escritos numa linguagem e num formato tal que eles consigam compreendê-los.

Até aqui foram apresentados alguns conceitos de organização da empresa. Muitas vezes acredita-se que, tendo chegado neste ponto, as coisas vão funcionar normalmente. Isto, infelizmente, não é verdade. O planejado algumas vezes não é executado. Outras vezes é executado, mas os resultados não são bons. E, ainda em outras situações, os resultados são bons em um dado momento, mas se tornam ruins com o tempo. Para se ter sucesso com a empresa é preciso dispor de ferramentas que auxiliem na garantia da qualidade dos processos. Estas ferramentas podem ser agrupadas em indicadores de desempenho, check list, anomalias, método de análise e solução de problemas, plano de auditoria e mural de administração visível. Trataremos aqui somente dos indicadores de desempenho, check list e anomalias.

\section{Indicadores de desempenho}

Os indicadores são o produto de um sistema de informações. Os indicadores servem para acompanhar se os protocolos estão corretos, se estão sendo cumpridos e, principalmente, se estão sendo atendidas as necessidades dos interessados no negócio. Isto significa que é preciso ter indicadores que mostrem se o negócio vai bem ou não.

Para que os indicadores sejam calculados há necessidade de se coletar dados. Os dados podem ser agrupados em dados zootécnicos (data do parto, produção de leite, etc.), dados financeiros (gastos, inventário, etc.) e dados gerais (precipitação, temperatura, etc.). Dado o grande número de indicadores que se pode ter na pecuária de leite, deve-se ter indicadores somente para aquilo que afete o resultado, ou seja, não se deve medir o que não for usado. Cada caso é um caso, cada fazenda deve definir quais são os seus indicadores e qual a freqüência que eles devem ser medidos. Não importa o número de indicadores, o que de fato importa é sua efetividade. Eventualmente, pode-se ter apenas um único indicador, desde que este seja útil. O que ocorre em muitas propriedades é que se têm centenas de indicadores, porém, estes não são utilizados.

Para a identificação dos indicadores deve-se, em primeiro lugar, caracterizar o(s) produto(s) da empresa, identificando os clientes externos e internos destes produtos. Deve-se perguntar para estes clientes quais os itens de qualidade que eles exigem para os produtos selecionados. Estes itens serão os itens de controle de produto. Em seguida, deve-se listar as tarefas que precisarão ser executadas para se obter os diferentes produtos, procurando priorizá-las de acordo com o impacto das mesmas sobre os itens de qualidade dos produtos. As tarefas principais devem possuir indicadores de verificação. Com isso será possível garantir a qualidade do produto final.

Como indicadores de produto teríamos, por exemplo, a contagem de células somáticas, a contagem bacteriana, a porcentagem de gordura e proteína do leite, o volume de leite entregue, além do custo de produção. Como exemplo de indicadores de verificação teríamos o índice de sujidade de tetos, a taxa de ocupação de camas, o tamanho relativo de partículas da dieta, a porcentagem de carboidrato não estrutural na dieta das vacas, a porcentagem de sobras de alimentos, as perdas de estoque, etc.

Deve-se ter indicadores somente para PO's já feitos e implementados, pois, sem rotina, não é possível que se tenha segurança nos números e, portanto, não se saberá se os processos estão fora de controle.

\section{O check list}

Os indicadores, como mencionado, permitem avaliaro desempenho do setor, do negócio e até do empregado, porém, são medidas que informam o que já ocorreu. É preciso desenvolver meios de se evitar que os problemas ocorram. Isto evitará retrabalho e levará a redução de custos. Este é o princípio do plano de controle de riscos originalmente criado para a indústria de alimentos "Análise de Perigos e Pontos Críticos de Controle-APPCC". Mas, mesmo assim, estarão sendo medidos o que já ocorreu. Para resolver o problema foi criada a ferramenta chamada check list. O check list é o conjunto de itens que devem ser verificados antes de se executar determinada tarefa. Reúne somente itens que, caso não estejam em ordem/ dentro das conformidades, impedem que a tarefa seja executada.

Fazendo uma analogia com ocheck list de um piloto de avião, seriam os itens que deveriam ser verificados antes da decolagem e que, se não estivessem adequados, poderiam fazer com que o avião viesse a cair. Ele deve ser executado pelo operador. Se algum item, ao ser checado, não estiver conforme, a tarefa não deve ser iniciada. Deve ser abortada imediatamente até que uma medida corretiva seja tomada. Caso o item a ser verificado não esteja conforme e mesmo assim a tarefa pode ser executada, então, este item, deve ser excluído do check list. Se o check list estiver $100 \%$ de acordo e mesmo assim o resultado esperado não estiver sendo atingido, o problema deixa de ser operacional e passa a ser técnico, ou seja, o procedimento é que não está correto. 
Identificação de problemas - anomalias

O check list não evita a ocorrência de imprevistos. Eles são as anomalias. Anomalia é qualquer ocorrência não esperada. Por exemplo, uma máquina que se quebra, falta de energia elétrica, uma pessoa que falta ao serviço, comida estragada, água ruim, cheiro estranho nos alimentos, vazamentos, sujeira, desordem, situações perigosas, iluminação inadequada, objetos danificados, fumaça, cheiro de queimado, presença de produtos químicos em local impróprio, poeira, ruídos estranhos em equipamentos, ausência de ruído característico, reclamações, calor ou frio excessivo, etc. Tudo aquilo que afetar o produto do setor é uma anomalia. Ocorrências sanitárias como mastite, metrite, etc. serão apontadas para o cálculo dos indicadores e não precisam ser anotadas como anomalias.

As anomalias são identificadas pelos operadores através do cinco sentidos (visão, tato, audição, paladar, olfato). Para solucioná-las devem ser adotadas contramedidas. Elas são de responsabilidade do operador, caso este tenha sido orientado e tenha autoridade para tanto, ou, então, implementadas pelo supervisor. Corrigida a anomalia, ela deve ser registrada, ou seja, deve ser feito um relatório de anomalias.

Cabe ao gerente a responsabilidade de avaliar as anomalias anotadas (quem resolve anomalias não é o gerente, este somente recebe a informação de sua ocorrência).

\section{Considerações Finais}

A implantação de um sistema de gestão envolve grande esforço mental e físico. Ele, no entanto, é fundamental para que se tenha sucesso/foco no negócio. Sem foco o empresário fica à deriva, ao sabor dos modismos e das “oportunidades de negócios". Ele fica sempre procurando o negócio milagroso. Isto não existe.

\section{Literatura Citada}

AMBROSIUS, J. Dairy farm personnel management workshop. Wisconsin, 1995.

Cornell Pro-Dairy Staff. “If I've told you once..." Northeast Dairy Business, v.2, n.2, 2000.

COVEY, S. The seven habits of highly successful people. New York: Simon and Schuster, 1990.

DRUCKER, P.F. A prática de administração de empresas. São Paulo: Thomson Pioneira, 1998.

FALCONI, V. Gerenciamento da rotina do dia-a-dia. Belo Horizonte: EDG, 1998.

MACHADO, P.F.; CASSOLI, L.D. Gestão de explorações leiteiras. Piracicaba; ESALQ, Clínica do Leite, 2006. 175p.

PRICE, B. Set monitoring protocols for SOP's. Dairy Herd Management, v.38, n.3, 2001 .

SCHOLTES, P.R. O Manual do líder: um guia para inspirar sua equipe e gerenciar o fluxo de trabalho no dia-a-dia. Rio de Janeiro: Qualitymark, 1999.

TYLER, D. The complete guide to managing agricultural employees. Indiana: 2001 .

WIERINGA, D.C.; MOORE, V.; BARNES. Procedure writing: principles and practices. Columbus: Battele Press, 1998. 